\title{
Assessing the osteopathic medical profession's progress
}

Three years ago, when a new format for the annual JAOA education issue was adopted, our goal was to provide a compendium of information on osteopathic medical education and a means to assess the profession's growth and development. As this current edition shows, important progress has been achieved in these 3 short years, as follows:

- There has been a dramatic increase in the number of approved and funded intern positions. As a result, graduating DOs are now assured of the availability of osteopathic internships and a wider choice of hospital location.

- Changes also have been made in the intern program curriculum to provide specialty tracks and more efficient utilization of the first postdoctoral training year for physicians preparing for residencies.

- More DOs are now in residency training in osteopathic institutions than ever before.

- Because of sweeping changes initiated and approved by the AOA Board of Trustees, DOs who have completed or are enrolled in nonAOA-approved allopathic residency programs can now have that training approved. The information offered in this annual education issue of the JAOA has been compiled by the AOA staff and the American Association of Colleges of Osteopathic Medicine. Updated statistics are presented on osteopathic medical students, osteopathic medical school finances, postdoctoral training, continuing education, and research.

Osteopathic medical education's progress during these past 3 years clearly shows that today's osteopathic medical student now enjoys a wider scope of educational and specialty choices than ever before. The future progress of the profession rests on this everexpanding base of educational development and responsiveness to meet the changing healthcare needs of Americans.

SANDRA M. WILLIAMSON Executive Editor 


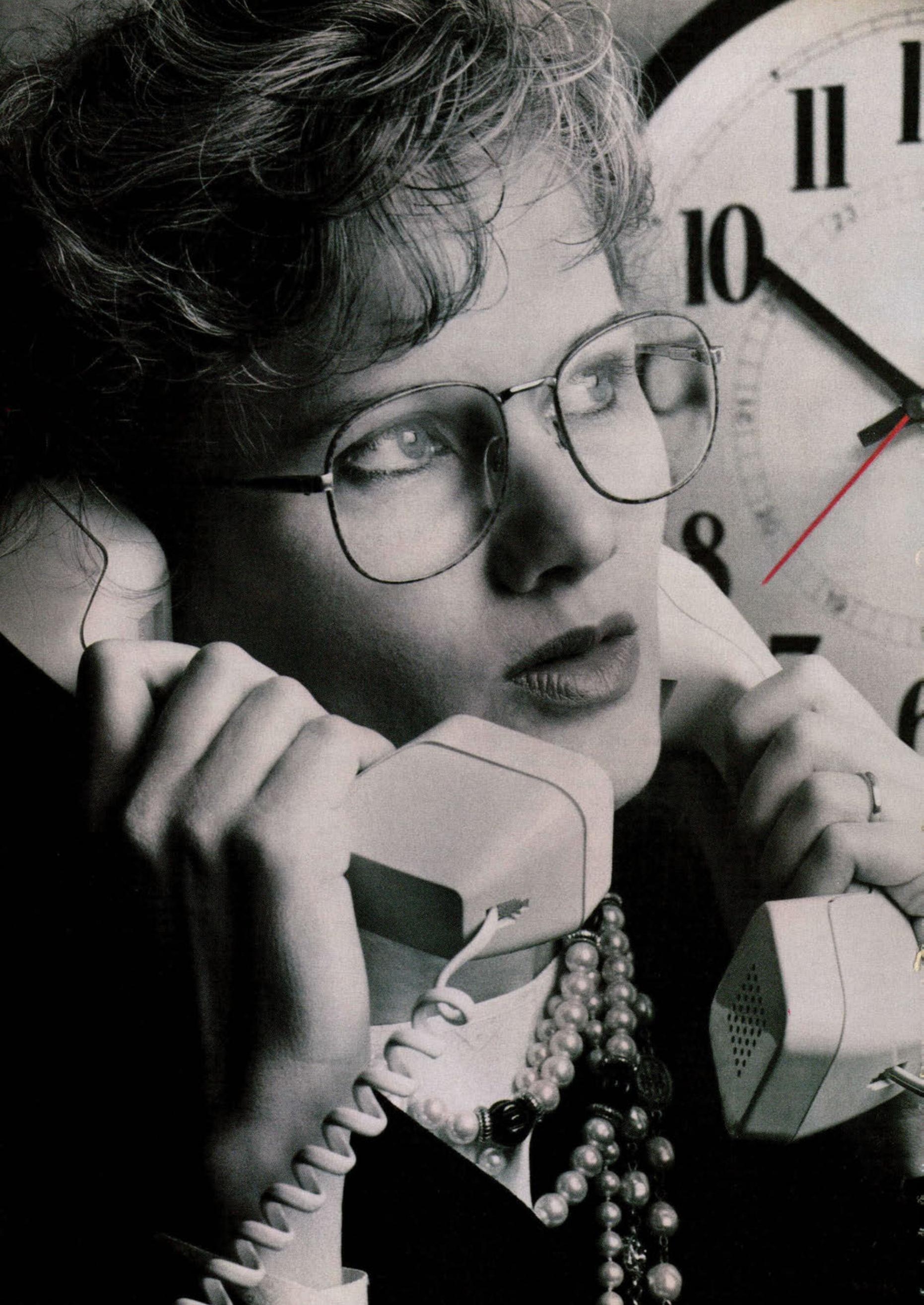




\section{THINK FAST. THINKSELDANE.}

Maximum on-the-job relief from the first dose through the season

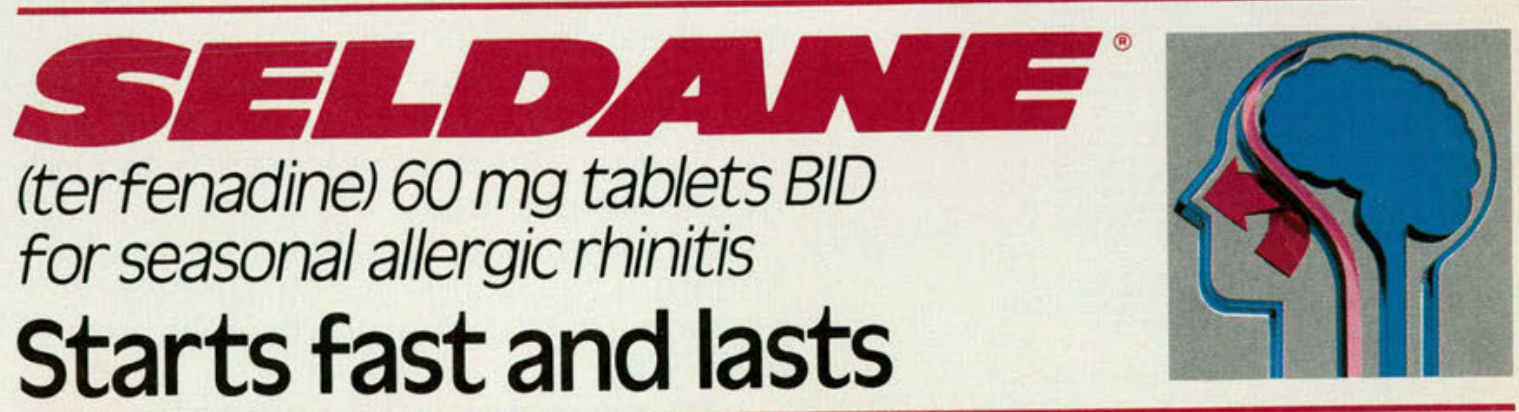




\section{Seldane $e^{\infty}$}

(terfenadine) $60 \mathrm{mg}$ Tablets

BAIEF SUMMARY

DESCRIPTION

Seldane (terfenadine) is svailable as tablets for oral administration. Each dients: corn starch, gelation, lactose, magnesium stoarate, and soo bicarbonate

INDICATIONS AND USAGE

Seldane is indicated tor the retief of symptoms associated with season allergic ming

CONTRAINDICATIONS

Selcane is contraindicatod in patients with a known typersensitivity

PRECAUTIONS

政 with impaired hepatic function (alcoholic cirrthosis, hepatitis), of of

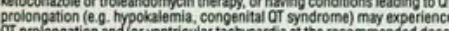

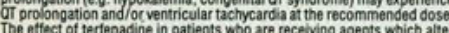
The effect of tertenadine in patients who are receiving agents which alte the orr interval is not known. These events have also occurred in patients
on macrolide antibiotics, including erythromycin, but causality is unclea. The events may be related to altered metabolism of the drug. to eiectrolye imbalance, or bot.

Information for patients: Patients taking Seldane should recelve the follion aliergic symptoms pregnancy or lactation only it the potentia benefit justifies the potential risk to fetus or baby, Padentas shou d be instructed to take Seldane only as need away from heat or direct sunlight, and away from children.

Orug Interactions: Preliminary evidence exists that concurrent ketocona.
2010 or macrolide administration significanty atters the metabolism

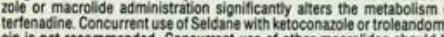
cin is not recommended.

Carcinoganesis, mutagenesis, impairment of ferti $x$ : Oral doses of terlenadine, corresponding to 63 times the recommended human dally dos. mince revealed no evidence of mutagenesis. Reproduction and fertility studies in rats showed noeffects on male or ferma but significant reouction in implants implantationlosses were observed, which were judged to be second aros. maternal toxicity.

Pregnancy Category C: There was no evidence of animal teratogenicity Reproduction studies have been performed in rats at doses 63 times an and lactation. There are no adequate and well-controlled studies in pregnant women. Seldane should be used during pregnancy only if the Nonteratogenic effects: Seldane is not recommended for nursing women. The drug has caused decreased pup weight gain and survival in rats given andlactation. Effects on pups exposed to Selicane onild during lactation are not known, and

Podiatric use: Safety and effectiveness of Seldane in children below the age

Experience from clinical studies, including both controlled and uncontrolled
studies involving more than 2,400 patients who received Seldane, provides

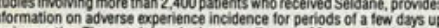
o six months. The usual dose in these studies was $60 \mathrm{mg}$ twice daily, bu or as high as $600 \mathrm{mg}$ daily

in controlled clinical studies using the recommended dose of $60 \mathrm{mg}$ b.i.d. the incicence of reported adverse effects in patients receving Selidane was ADVERSE EVENTS REPORTED IN CUINICAL TRIALS

\begin{tabular}{|c|c|c|c|c|c|}
\hline \multirow[b]{2}{*}{$\begin{array}{l}\text { Aovene } \\
\text { Eent }\end{array}$} & \multicolumn{5}{|c|}{ Present of Pelients Reporting } \\
\hline & \multicolumn{3}{|c|}{ 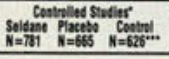 } & \multicolumn{2}{|c|}{ 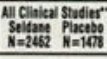 } \\
\hline $\begin{array}{l}\text { Central Nervous System } \\
\text { Orowsiness }\end{array}$ & 90 & & & & \\
\hline Headache & 63 & 7.4 & 3.8 & 15.8 & 112 \\
\hline Fatique & 29 & 0.9 & 5.8 & 45 & 30 \\
\hline Diziness & 14 & 1.1. & 10 & 1.5 & 12 \\
\hline Nencousness & 0.9 & 02 & 0.8 & 17 & 1.0 \\
\hline Weakness & 0.9 & 0.5 & 0.2 & 0.6 & 0.5 \\
\hline Aopetite increase & 0.6 & 00 & 0.0 & 0.5 & 0.0 \\
\hline 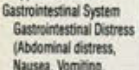 & & & & & \\
\hline 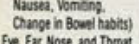 & 46 & 30 & 2.7 & 7.6 & 5.4 \\
\hline $\begin{array}{l}\text { Eye, Ear, Nose, nod Trout } \\
\text { Dry Mouth/Nose/Throe }\end{array}$ & 23 & 1.8 & 3.5 & 48 & 3.1 \\
\hline Cough & 09 & 0.2 & os & 2.5 & 1.7 \\
\hline Sore Throot & 0.5 & 0.3 & 0.5 & 3.2 & 18 \\
\hline Epostax's & 00 & 0.8 & 02 & 0.7 & 0.4 \\
\hline & & & & & \\
\hline and unticaria) or itcting & 1.0 & 1.7 & 1.4 & 16 & 20 \\
\hline
\end{tabular}

"Duration of treatment in "CONTROLLED STUDIES" was usually $7-14$ "Duration of treatment in "ALL CLINICAL STUDIES" was up to 6 months. CONTROL ORUGS: Chlorpheniramine (291 pas
mine (189 patients). Clemastine (146 patients)

Rare reports of severe cardiovascular adverse effects have been received Which include artity thmias (ventricular tactyambythmia, torsades de pointes.

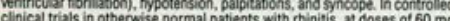
bi.d. small increases in OTc interval were observed. Changes of this magnitude in a normal population are of doubttul clinical significance. owevec in another study $(\mathrm{N}=20$ patients) at $300 \mathrm{mg}$ b i. . a mean increase observed without clinical signs or symptoms.

perted in clinical trials (see Table), adverse efftects have been reported at a lower incidence in clinical trials and/or spontaneously during marketing of Seldane that warrant list. cia (hair loss or thinning), anaphylaxis, angioedema, bronchospasm. contusion, depression, galactortheatinsomnia, menstrual disorders (ncludingdoysmenorrhea), musculoskeletal symptoms, nightmares, paresthesia,
photosensitivity, seizures, sinus tachycardia, sweating, tremor, urinary

In clinical trials, several instances of mild, or in one case, moderate trans. ces include isolated reports of aundice, cholestatic hepastis, and hepattis. In most cases OVERDOSAGE

Intormation concerning possitite
Full Prescribing information.

DOSAGE ANO ADMINISTRATION

One tablet $(60 \mathrm{mg})$ twice dasily for adults and children 12 years and older. MARION MERPEI DS of Juyy, 1990 Prescription Products Division
Kansas City, M0 64114

\section{5 months old. 2 packs a day.}
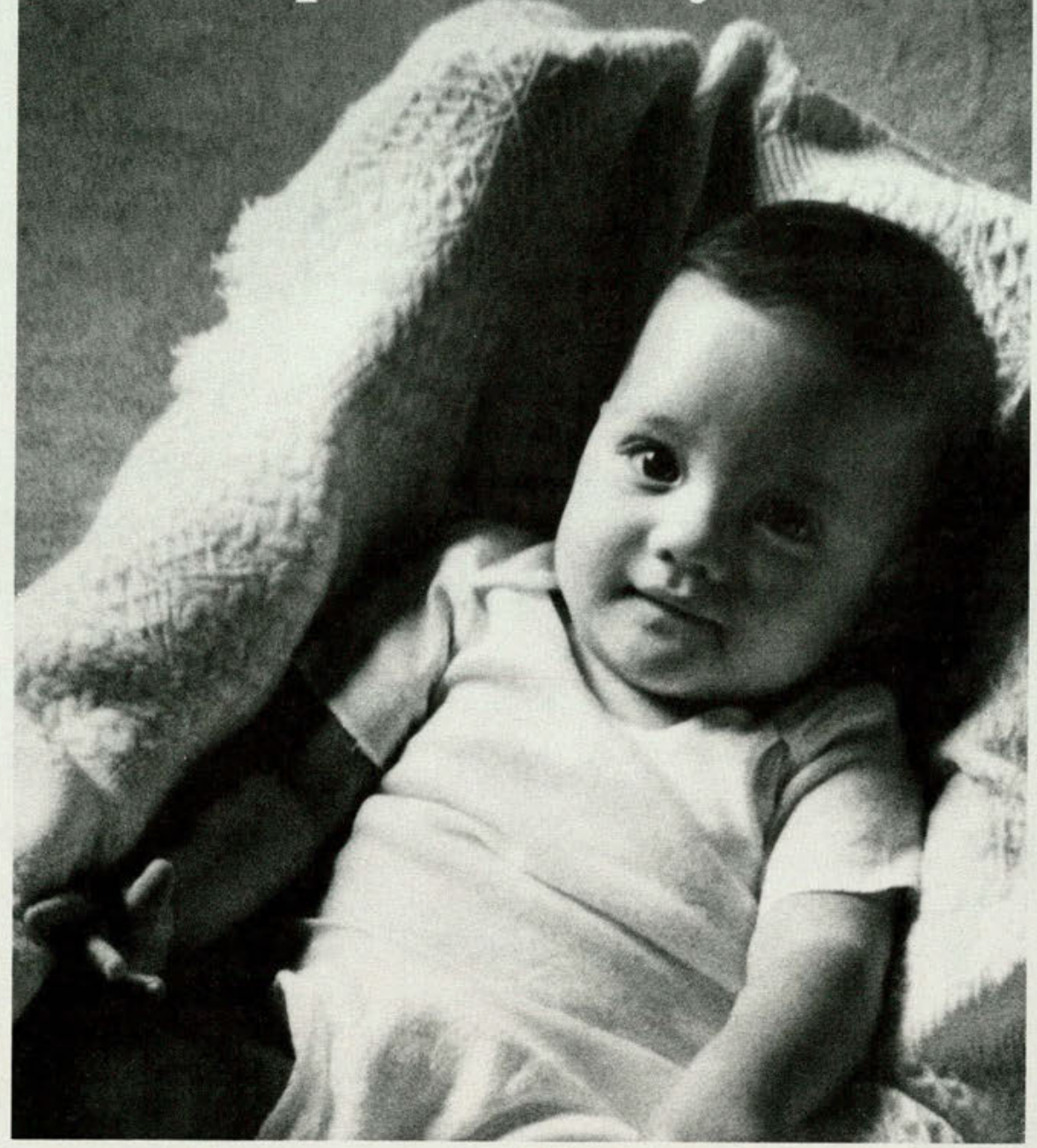

This is David Jr. He's a smoker. But not by choice. You see, when David's parents smoke around him, he's smoking too.

And babies who breathe tobacco smoke are twice as likely to have chronic or recurring respiratory illnesses, according to both the 1986 U.S. Surgeon General's Report on Passive Smoking and a 1986 report issued by the National Research Council's Committee on Passive Smoking.

In America, $42 \%$ of all children under one year old live with at least one smoker. You can change that.

Warn your patients about the danger And until you're able to help them quit, recommend that they don't smoke around their baby.

TELL THEM NOT TO SMOKE. THERE'S A BABY IN THE HOUSE. 